\title{
SISTEMÁTICA PARA SELEÇÃO DE UM PORTFÓLIO DE ESTRATÉGIAS DE POSTERGAÇÃO PARA CADEIAS SUPRIMENTOS
}

\section{SISTEMATIC FOR SELECTING A POSTPONEMENT STRATEGY PORTFOLIO FOR SUPPLY CHAINS}

\author{
Luiz Eduardo Simão ${ }^{1}$; Mirian Buss Gonçalves ${ }^{2}$ \\ ${ }^{1}$ Universidade Federal de Santa Catarina - UFSC - Florianópolis - SC - Brasil \\ luiz.es@posgrad.ufsc.br \\ ${ }^{2}$ Universidade Federal de Santa Catarina - UFSC - Florianópolis - SC - Brasil \\ mirianbuss@deps.ufsc.br
}

\begin{abstract}
Resumo
A estagnação da economia tem aumentado à competição e a incerteza no setor industrial. Tendencias como o aumento na proliferação da variedade de produtos e a exigencia por customização de produtos, tem contribuído para dificultar a previsão da demanda, devido ao aumento da incerteza da demanda dos produtos finais. Nesse novo contexto competitivo, não é possivel mais empregar o processo da cadeia suprimentos tradicional "um formato atende a todos" ("one-size-fits-all") com políticas únicas para todos os produtos porque esta prática pode levar a perdas de rentabilidade significativas, devido ao aumento nos niveis de estoque e vendas perdidas. No entanto, a pesquisa em cadeias de suprimentos tem dado relativamente pouca atenção para a necessidade de empregar diferentes estratégias de cadeia de suprimentos de forma segmentada bem como desenvolver e gerenciar essas múltiplas estratégias de cadeias de suprimentos de forma simultanea. Assim, o presente artigo tem como objetivo apresentar uma abordagem para seleção de um portfólio de estratégias de postergação baseado na para segmentação da cadeia de suprimentos baseada na análise do perfil da demanda (análise volume-variedade) e uma ferramenta para auxiliar na seleção de estratégias de postergação impulsionado pelo segmento de clientes-produtos e de suas respectivas proposições de valor.
\end{abstract}

Palavras-chave: cadeia de suprimentos; segmentação; postergação; portfólio.

\section{Introdução}

A estagnação da economia tem aumentado à competição e a incerteza no setor industrial com tendencias como aumento da variedade de produtos e customização de produtos e o consequente aumento da incerteza da demanda. Esses fatores proporcionam desafios de gestão adicionais e novas práticas na forma com que as cadeias de suprimentos são projetadas e gerenciadas. Neste novo contexto competitivo, não é possível empregar um tradicional processo "um formato atende a todos" ("one-size-fits-all") e políticas únicas, porque esta prática leva a 
quedas significativas na rentabilidade pela fuga do fluxo de caixa e vendas perdidas (THOMAS, 2012). Comprovando esta tendencia, verifica-se que nos últimos anos, algumas das melhores cadeias de suprimentos (Apple, Dell, Zara, etc) vem transformando suas cadeias em um modelo segmentado multicanal com políticas diferentes para servir diferentes categorias de clientes (por exemplo: individuais, empresas, distribuidores e varejistas). No entanto, a revisão da literatura revelou que relativamente pouca atenção para a necessidade de empregar diferentes chainstrategies abastecimento simultâneo, e como desenvolver e gerenciar essas estratégias múltiplas cadeias de suprimentos.

No novo contexto competitivo industrial, as estratégias da cadeia de suprimentos selecionadas devem ser então robustas o suficiente para lidar com a incerteza, uma vez que recentemente é a incerteza rege a cadeia de suprimentos (GEARY, CHILDERHOUSE e TOWILL, 2002). Considerando a incerteza da cadeia de suprimentos, as estratégias de postergação (adiamento) parecem ser uma resposta estratégica natural contra a incerteza, uma vez que atrasa as atividades da cadeia de suprimentos até o último momento possível (YANG e BURNS, 2003). Com base nisso, o presente artigo desenvolve a visão de que as diferentes estratégias de adiamento podem ser usadas em vários pontos da cadeia de fornecimento em simultâneo. Assim, o objetivo deste artigo é desenvolver uma carteira de cadeia de fornecimento.

Neste novo contexto competitivo, não é possível empregar um processo da cadeia tradicional "um formato atende a todos", porque esta prática leva a perdas de rentabilidade significativas, por fugas no fluxo de caixa e vendas perdidas (THOMAS, 2012). No entanto, a revisão da literatura revelou a existência de relativamente pouca atenção para a necessidade de empregar diferentes estratégias de cadeia de suprimentos ao mesmo tempo, bem como desenvolver e gerenciar essas múltiplas estratégias de cadeias de suprimentos. Assim, o presente artigo apresenta uma metodologia para seleção de um portfólio de estratégias de postergação baseado na segmentação da cadeia de suprimentos.

\section{Revisão da literatura}

Existem três elementos chave da cadeia de suprimentos identificados por Lambert; GarcíaDastugue e Croxton (2005), necessários para tornar os produtos disponíveis para os clientes: (1) a rede da cadeia de suprimentos; (2) os processos da cadeia de suprimentos que operam e apoiam a rede; e (3) as decisões da cadeia de suprimentos necessários para a gestão da rede. Uma rede da cadeia de suprimentos pode ser definida como "a infra-estrutura (fornecedores, centros de produção e armazéns) e o material (matéria-prima, trabalho em processo, e estoque de produtos acabados) que flui entre as instalações para satisfazer demanda do cliente final (SIMCHI-LEVI, 
KAMINSKI, SIMCHI-LEVI, 2003). Por outro lado, os processos da cadeia de suprimentos são definidos como o conjunto de atividades utilizadas para realizar o movimento do material através da rede da cadeia de suprimentos, sendo que os processos da cadeia de suprimentos incluem tanto os processos produção e de logística (CSCMP, 2010). Em particular, os processos de logística incluem as atividades relacionadas com os fluxos e armazenamento direto e reverso, de bens, tais como transporte e armazenagem. Finalmente, a gestão da cadeia de suprimentos representa as decisões de gestão (planejamento, organização, execução e controle) dos processos da cadeia de suprimentos, necessários para o gerenciamento de toda a rede da cadeia de suprimentos. Uma tarefa chave no processo de gestão é selecionar a estratégia da cadeia de suprimentos mais adequada para satisfazer demanda do cliente final.

\subsection{Estratégias da cadeia de suprimentos}

A gestão da cadeia de suprimentos tem foco no cliente final, de forma a ser mais sensível às mudanças na demanda do cliente final (LAMBERT, 2006). Como os clientes tem necessidades e demandas diferentes, são necessárias diferentes estratégias de cadeia de suprimentos (eficiente e responsiva) quando os produtos são funcionais ou inovadores (FISHER, 1997). LEE (2002) expandiu o conceito de FISCHER (1997) e considera que existem quatro diferentes tipos de estratégias de cadeias de suprimentos que podem ser utilizadas para lidar com a incerteza, são elas:

1) Cadeias de abastecimento eficientes - estas são cadeias de suprimentos onde as decisões de produção e distribuições são baseadas em previsões de longo prazo. Estas cadeias de suprimentos utilizam estratégias destinadas a criar as maiores eficiências de custos na cadeia de suprimentos. Para que tais eficiências a serem alcançadas as atividades que não agregam valor devem ser eliminadas e as economias de escala devem ser perseguidas;

2) Cadeias de suprimentos com cobertura de risco - estas são as cadeias de suprimentos que utilizam estratégias de agrupamento e compartilhamento de recursos na cadeia de suprimentos, de modo que o risco de interrupção de suprimento também pode ser compartilhado. Estas cadeias de suprimentos tem alta incerteza no suprimento, mas uma baixa incerteza da demanda;

3) Cadeias de suprimentos responsivas - estas são as cadeias de suprimentos que utilizam estratégias destinadas a ser ágil e flexível para a mudança e diversas necessidades dos clientes. Trata-se de cadeia de suprimentos, onde as decisões de produção e de distribuição são função da procura; 
4) Cadeias de suprimentos ágeis - estas são as cadeias de suprimentos que têm a capacidade de ser sensível às diversas e imprevisíveis mudanças nas demandas de clientes enquanto minimiza o risco de interrupção do fornecimento. Utiliza estratégias destinadas a ser ágil e flexível às necessidades dos clientes, enquanto que o risco de escassez de oferta ou interrupções é coberta através do compartilhamento de risco do inventário ou de outros recursos de capacidade. Estas são as cadeias de suprimentos híbridas que combinam os pontos fortes de cadeias de suprimentos com cobertura de risco e responsivas. Trata-se de cadeia de suprimentos, onde algumas fases da cadeia de suprimentos são empurradas enquanto outros estágios empregam uma estratégia puxada.

Considerando a diferentes opções de escolha das estratégias, a seleção da estratégia cadeia de suprimentos deve ser baseada na criação de soluções adequadas para satisfazer as necessidades de diferentes segmentos de valor dos clientes (HILLETOFTH, 2009).

\subsection{Segmentação da cadeia de suprimentos}

A segmentação da cadeia de suprimentos é o processo de análise dos clientes e suas necessidades de forma a projetar um conjunto de opções de cadeia de suprimentos que você pode recorrer para melhor atendê-los (MELLINS-COHEN, 2012). A literatura tem sido apoiada na necessidade de uma configuração da cadeia de suprimentos com base em diferentes segmentos de clientes. $\mathrm{O}$ argumento inicial foi de que a logística precisa ser diferenciada para atender às necessidades específicas dos clientes (FULLER et al 1993;. SHAPIRO, 1994; MURPHY e DALEY, 1994), sendo que recentemente essa visão foi confirmada empiricamente (MENTZER, 2004). No contexto da cadeia de suprimentos, o caso de segmentação para produtos específicos foi tratado pela primeira vez por Fisher (1997), com base em uma distinção entre produtos funcionais ou inovadores e cadeias de suprimentos eficientes ou responsivas. Gattorna (1998) considerou que os clientes podem ser segmentados com base em seus comportamentos de compra e a estratégia da cadeia de suprimentos pode ser desenvolvida para atender as exigências dos segmentos individuais. Mais recentemente, a literatura de segmentação de cadeias de suprimentos propõem taxonomias estendidas como base que compreendem critérios, tais como: produto (padrão ou especial), demanda (estável ou instável), prazos (curto ou longo), volume (alto e baixo) e o tempo de entrega (curto ou longo) (CHRISTOPHER e TOWILL, 2002; CHILDERHOUSE, AITKEN, e TOWILL, 2002). A segmentação de cadeias de suprimentos deve ser impulsionada por uma proposta de valor única oferecida para uma determinada categoria de clientes para um determinado produto (THOMAS, 2012) e esta proposta de valor pode incluir o preço, a 
quantidade, os prazos de entrega, o grau de flexibilidade para cada segmento cliente-produto, entre outros.

\subsection{Estratégias de postergação}

O principal objetivo da estratégia de postergação é atrasar as atividades da cadeia de suprimentos (ou seja, projeto, compras, montagem, produção, embalagem, distribuição, etc.) até o último momento possível ou até depois de pedidos de clientes forem recebidos (VAN HOEK, 2001). Geralmente, dois tipos de postergação são utilizados: (1) postergação de produção; e (2) postergação logística. A postergação da produção atrasa a finalização do produto (forma) até que os pedidos dos clientes sejam recebidos. Existem quatro tipos de postergação de produção: fabricação, montagem, embalagem e rotulagem (VAN HOEK, 2001). Por outro lado, a postergação de logística (tempo e lugar) implica atrasar o movimento para frente (distribuição) de produtos o maior tempo possível na cadeia de suprimentos, e que os produtos são mantidos em armazenamento em locais centrais na cadeia de distribuição (BOWERSOX e CLOSS, 1996). Entretanto, a abordagem moderna da postergação exige uma completa visão da cadeia de suprimentos (YANG e BURNS, 2003) e por isso, pode tomar quaisquer novos formatos como: postergação do produto (BROWN, LEE e PETRAKIAN, 2000); postergação de preço (VAN MIEGHEM e DADA, 1999); postergação de desenvolvimento de produto e postergação de compras (YANG, BURNS e BACKHOUSE, 2004).

\subsection{Alinhando as estratégias de cadeias de suprimentos e estratégias de postergação}

O valor da estratégia de postergação cresce com o aumento da incerteza de previsão da demanda e com a proliferação de uma grande variedade de produtos (JOHNSON e ANDERSON, 2000), e é reduzida com a redução do tempo de resposta exigido pelo cliente. Dessa forma, fatores como a incertezas da demanda e a incerteza do suprimento, além do prazo de entrega exigido pelo cliente e grau de customização dos produtos podem ser usados como fatores direcionadores para selecionar a estratégia de postergação e a estratégia de cadeia de suprimentos mais adequados a cada situação. A Figura 1 ilustra as relações para combinar estratégias da cadeia de suprimentos e as diferentes estratégias de postergação e os quatro fatores direcionadores de seleção. Na Figura 1 a caixa A representa produtos com características funcionais e a estratégia da cadeia de suprimentos de cobertura de risco. Esta estratégia de cadeia de suprimentos é adequada para os produtos funcionais com baixa incerteza da demanda, mas alta incerteza de abastecimento, baixa flexibilidade do produto e longo prazo de entrega ao cliente, são capazes de usar a estratégia de postergação da produção (fabricação, montagem, embalagem e rotulagem), postergação de 
logística e postergação de compras. Aqui, o longo tempo de espera aceito pelo cliente e a elevada incerteza oferta impulsiona escolha da estratégia de postergação apropriada.

Figura 1 - Alinhando estratégias da cadeia de suprimentos e estratégias de postergação

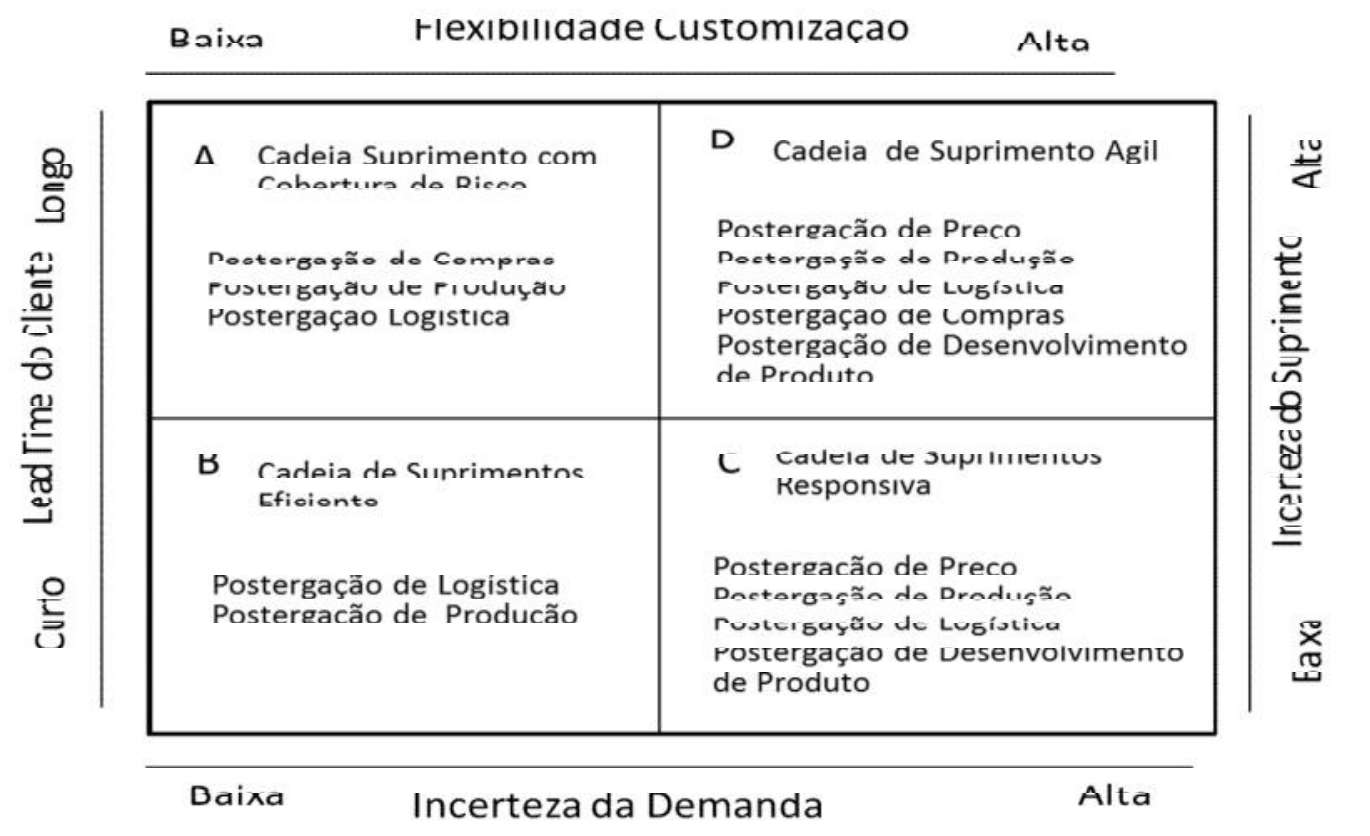

Fonte: Autoria prórpia (2014)

A caixa B está relacionada com o produto funcional e uma estratégia eficiente cadeia de suprimentos. Neste caso, o grau de flexibilidade para customização do produto é baixa, a incerteza demanda e do abastecimento são baixos, mas o tempo de resposta exigido pelo cliente é curto. Geralmente, são produtos padronizados e utilizam a estratégia de especulação, pois os custos e economias de escala são fatores importantes. Por outro lado, os produtos com as características inovadoras da caixa $\mathrm{C}$, apresentam alta incerteza da demanda, mas baixa incerteza de abastecimento, alto grau de personalização do produto e prazo de entrega cliente curto. A estratégia adequada e uma cadeia de suprimento responsiva. Neste caso, a proliferação da variedade de produtos e prazos de entrega curtos impulsiona a estratégia de postergação mais apropriada a escolher. Para os produtos da caixa $\mathrm{C}$ é viável que as empresas possam adiar os processos de produção (fabricação, montagem, embalagem e rotulagem), de logística, de compras e o de desenvolvimento de produtos. Por fim, os produtos na caixa D têm características inovadoras e a estratégia de cadeia de suprimentos ágil é apropriada. Aqui é possível que as empresas possam alcançar um elevado nível de postergação, incluindo todas as tipologias: postergação preço, postergação de produção (fabricação, montagem, embalagem e rotulagem), postergação de logística, de compras e postergação de desenvolvimento de produtos. Produtos na caixa de D são impulsionados pelo alto grau de incerteza da demanda e do suprimento, o alto grau de personalização do produto e pelo longo prazo de entrega aceito pelo cliente. 
A seguir, é proposta uma metodologia para seleção de um portfolio de postergação para cadeia de suprimentos com base em segmentação de clientes e produtos.

\section{Metodologia para seleção de um portfolio de estratégias de postergação para cadeias de suprimentos}

Este artigo tem como objetivo o desenvolvimento de uma metodologia para seleção de um portfolio de estratégias de postergação com base na segmentação da cadeia de suprimentos. A metodologia é apresentada na Figura 2 e indica, inicialmente, que é preciso entender o que é valor para o cliente com base nos critérios ganhadores de pedidos.

Figura 2 - Metodologia para seleção de um portfolio postergação baseada na segmentação da cadeia de suprimentos

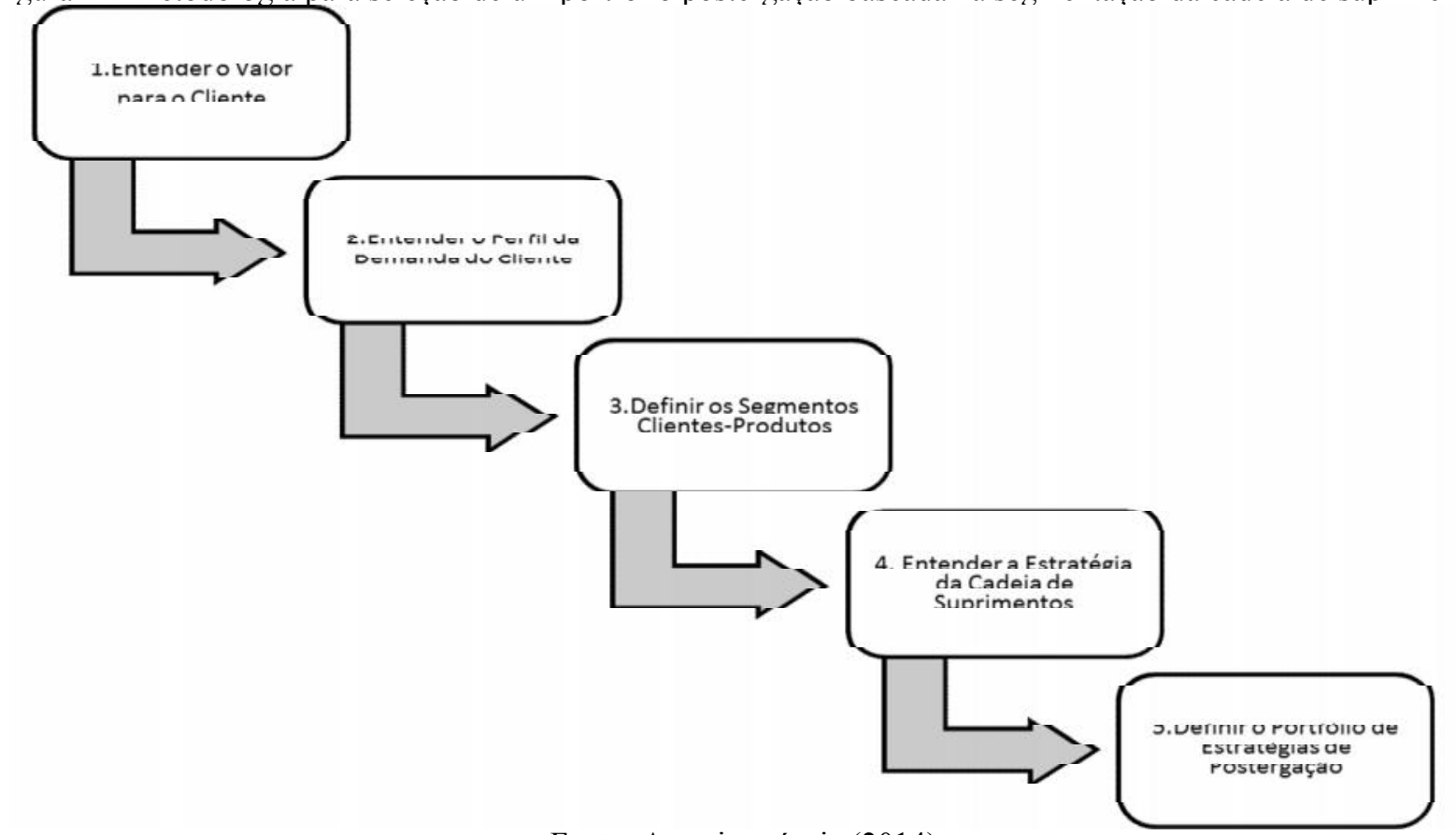

Fonte: Autoria própria (2014)

Para tanto, uma pesquisa deve ser realizada com os clientes para especificar a extensão em que os diferentes critérios ganhadores de pedidos são importantes para atingir seus objetivos de negócio (por exemplo: preço do produto, design de produto, serviço de pós-venda, confiabilidade de entrega, variedade de produtos, etc.) Em seguida, cada cliente deverá então ser convidado a atribuir importância a cada critério ganhador de pedido usando a escala Likert de cinco pontos, variando de (1) totalmente sem importância a (5) muito importante. O foco dessa etapa é identificar e explorar aos diferentes segmentos de clientes com base no valor de importância atribuída a cada um destes fatores, para ver quais os padrões de resposta são encontrados. A primeira etapa na análise dos critérios ganhadores de pedidos é calcular a média para cada uma das variáveis, baseado no total da amostra, o que indica a importância relativa da amostra ligada 
aos vários critérios ganhadores de pedidos. Em seguida, deve ser realizada uma análise dos segmentos dos entrevistados para avaliar a consistência de opinião dentro da amostra em relação à importância relativa dos critérios ganhadores de pedidos. A análise do agrupamento dos resultados produzidos determinou os grupos que diferem na ênfase que se aplicam aos 12 critérios ganhadores de pedido. Nessa etapa, fatores geográficos, de rentabilidade e variáveis demográficas podem ser usados como filtros das diferenças e estabelecer os segmentos de forma mais significativa (GODSELL et al, 2010).

Depois de entender os clientes, o segundo passo da metodologia é entende o perfil da demanda dos produtos ofertados ao mercado, uma vez que a sua natureza e variabilidade associada permitem às empresas gerir de forma mais eficiente e aperfeiçoar suas operações para atender às reais necessidades do mercado (VITASEK, MANRODT e KELLY, 2003). A análise do perfil da demanda deve ser realizada por meio de análise de volume-variabilidade, considerando o volume da demanda mensal no nível de produto acabado e a variabilidade através da razão entre o desvio padrão da demanda e o desvio médio da demanda do cliente, e o número adimensional resultante é chamado de coeficiente de variação (CV). De acordo com GODSELL et al (2010), baixos valores de CV (ou seja, menos do que 0,4 ) estão associados com uma baixa incerteza da demanda desse produtos. Por outro lado, valores mais elevados (ou seja, superiores a 0,4) estão associados com uma alta incerteza da demanda. A análise do volume-variabilidade permite às empresas classificar os produtos em diferentes categorias principais.

O terceiro passo da metodologia é a definição de um segmento de cliente-produto adequado com base nos agrupamentos comuns de critérios ganhadores de pedidos e do perfil da demanda. O objetivo nesta etapa é entender quais combinações clientes-produtos são critérios ganhadores de pedidos e quais deveriam ser suas propostas de valor. Já a quarta etapa da metodologia proposta é compreender a resposta estratégica necessária da cadeia de suprimentos, para oferecer as diferentes propostas de valor aos seus clientes com base no tipo de produto encomendado. Finalmente, a quinta etapa da metodologia é selecionar as diferentes estratégias de postergação para os diferentes segmentos clientes-produtos e proposições de valor identificadas, que sejam alinhadas a estratégia de postergação (ver Figura 1). Para ilustrar o uso da metodologia para seleção de um portfólio de estratégias de postergação com base na segmentação da cadeia de suprimentos, na próxima seção um estudo de caso brasileiro é apresentado.

\section{Estudo de caso}

Um grande fabricante de motores elétricos brasileiro faz e oferece uma linha completa de motores para várias aplicações, incluindo equipamentos, transporte, energia e marítimo. Na 
verdade, o fabricante prove uma grande variedade de produtos finais, com base em numa abordagem única para todos os clientes. No entanto, esta abordagem resultou em precisão muito baixa de previsão e, consequentemente, níveis elevados de estoques e um nível de serviço ao cliente muito baixo (abordagem empurrada). Entretanto, os motores são altamente configuráveis, e, nos últimos anos muito dos clientes estão requisitando uma configuração personalizada dos produtos finais. Recentemente, o fabricante analisou e segmentou sua cadeia de suprimentos, a fim de oferecer diferentes proposições de valor para os seus clientes com base em estratégias de postergação. Assim, seguindo a metodologia proposta, inicialmente, os dados primários foram coletados a partir de pessoal de nível superior (por exemplo, diretores e gerentes de manufatura e de logística) e cerca de 1.600 questionários foram enviados por e-mail para os principais clientes. Desse total, aproximadamente 357 clientes se recusaram a participar da pesquisa. Ao final, 1.242 questionários foram devolvidos respondidos, o que representa uma taxa de resposta de $77 \%$ do total dos questionários enviados. A principal pergunta desta pesquisa pediu aos clientes para especificar a extensão com que os 12 critérios ganhadores de pedidos definidos são importantes para atingir seus objetivos de negócio: (1) preço do produto; (2) projeto de produto; (3) serviço de pós-venda; (4) confiabilidade de entrega; (5) entrega no prazo; (6) entrega rápida; (7) minimização de custos; (8) variedade de produtos; (9) flexibilidade de mudanças no mix; (10) flexibilidade para mudanças de volume; (11) flexibilidade para customização do produto; e (12) disponibilidade do produto. Cada entrevistado foi convidado a atribuir a importância a cada critério ganhador de pedido usando a escala Likert de cinco pontos, variando de (1) totalmente sem importância a (5) muito importante. A primeira etapa do estudo foi calcular a média para cada um dos critérios ganhadores de pedidos com base na amostra total de 1.242 clientes que responderam. Um exame da ordem de classificação das 12 dimensões, apresentados no Quadro 1, indica a importância relativa da amostra anexada aos vários critérios.

Tabela 1 - Ranking critérios ganhadores de pedidos do cliente

\begin{tabular}{|c|c|}
\hline Fatores Ganhadores de Pedido & Média \\
\hline 1. Entrega no Prazo & 5,0 \\
\hline a. Flaribilidade para Cuotomilear & 1,0 \\
\hline 3. Entrega Rápida & 4,6 \\
\hline 4. Disponibilidade do Produto & 4,5 \\
\hline 5. Preço do Produto & 4,4 \\
\hline C. Wortodododon-odktose & 1,2 \\
\hline $\begin{array}{l}\text { 7. Flexibilidade Mudanças no Volume } \\
\text { 8. Minimização de Custos }\end{array}$ & $\begin{array}{l}4,2 \\
4,1\end{array}$ \\
\hline Y. HIexıbIIdaae IVIuaanças no Mix & 4,0 \\
\hline In Confiahilidadana Entraga & 2,0 \\
\hline $\begin{array}{l}\text { 11. Serviço Pós Venda } \\
\text { 12. Projeto do Produto }\end{array}$ & $\begin{array}{l}3,8 \\
3,5\end{array}$ \\
\hline
\end{tabular}

Fonte: Pesquisa de campo (2014) 
A segunda etapa da análise envolveu uma análise de segmento dos entrevistados para avaliar a consistência de opinião dentro da amostra em relação à importância relativa dos critérios ganhadores de pedidos. O objetivo da análise dos segmentos foi agrupar os clientes que tinham avaliado os critérios ganhadores de pedido de forma semelhante. Usando o gráfico de radar apresentado na Figura 3, para cada resposta ao cliente relacionado à ordem dos critérios ganhadores de pedidos, permitiu realizar o agrupamento de segmentos com opiniões similares. Conforme ilustrado na Figura 3, clientes com perfil de fatores ganhadores de pedidos e importância semelhantes, como os clientes C e D, formaram um grupo, enquanto, clientes como A e B foram agrupados em outros três grupos. Em resumo, foram identificados quatro segmentos de clientes-produtos: (1) Preço do Produto; (2) Entrega rápida; (3) Variedade de produtos; e (4) Flexibilidade para personalização.

Figura 3 - Segmentação dos clientes pelos fatores ganhadores de pedidos
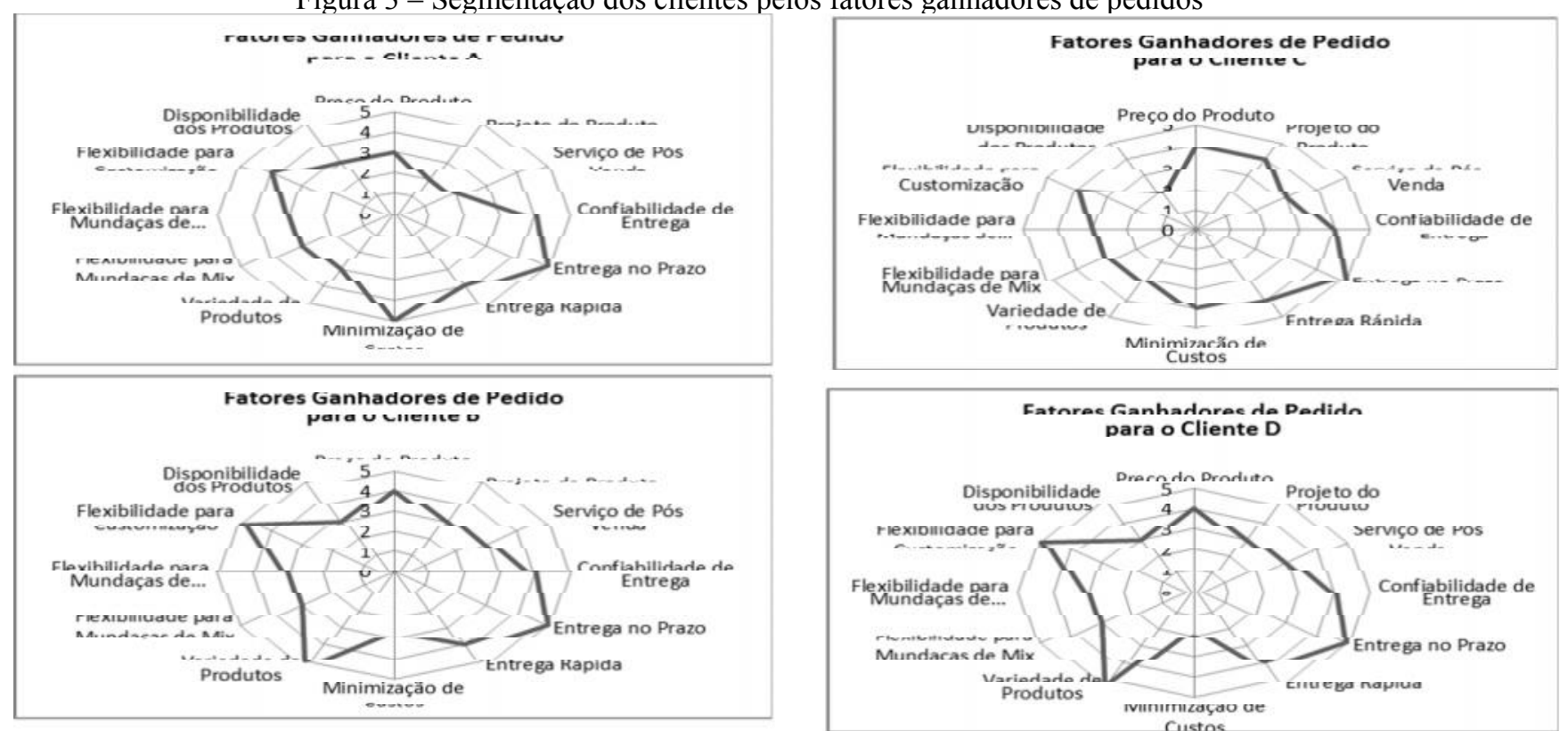

Fonte: Autoria própria (2014)

Na segunda etapa da metodologia foi realizada a análise do perfil de demanda com base em dados do período de 35 meses (2009-2012) para todos os 3.077 diferentes produtos individuais que foram fornecidos aos clientes. Os dados foram fornecidos em base mensal em nível de item individual. Uma análise do perfil de demanda foi classificada com base tanto no seu volume (em unidade) e na sua variabilidade da demanda (representada pelo coeficiente de variação $=$ desvio padrão / demanda média). A Figura 4 mostra o quadro de análise do perfil da demanda baseado no volume de variabilidade para o estudo de caso. Verifica-se pela Figura 4 que 24,71\%, (760 itens) do total dos itens possuem valores do coeficiente de variação da demanda (CV) abaixo de 0,4, enquanto $75,29 \%$ (2.316 itens) do total dos itens apresentam valores do coeficiente de variação da 
demanda (CV) acima de 0,4. Em termos práticos, isso significa que uma pequena parcela dos itens tem uma baixa incerteza da demanda $(\mathrm{CV}<0,4)$, enquanto a grande maioria dos itens vendidos tem uma alta incerteza da demanda $(\mathrm{CV}>0,4)$. Além disso, a análise do perfil identificou que $34,79 \%$ dos itens (1.070 itens) têm volumes até 1.000 unidades, 44,57\% (1.371 itens) tem volume variando de 1.000 a 10.000 unidades e apenas 19,34\% dos itens (595 itens) tem volumes entre 10.000 e 100.000 unidades, e, acima de 100.000 unidades apenas $1,3 \%$ ou 40 itens do total.

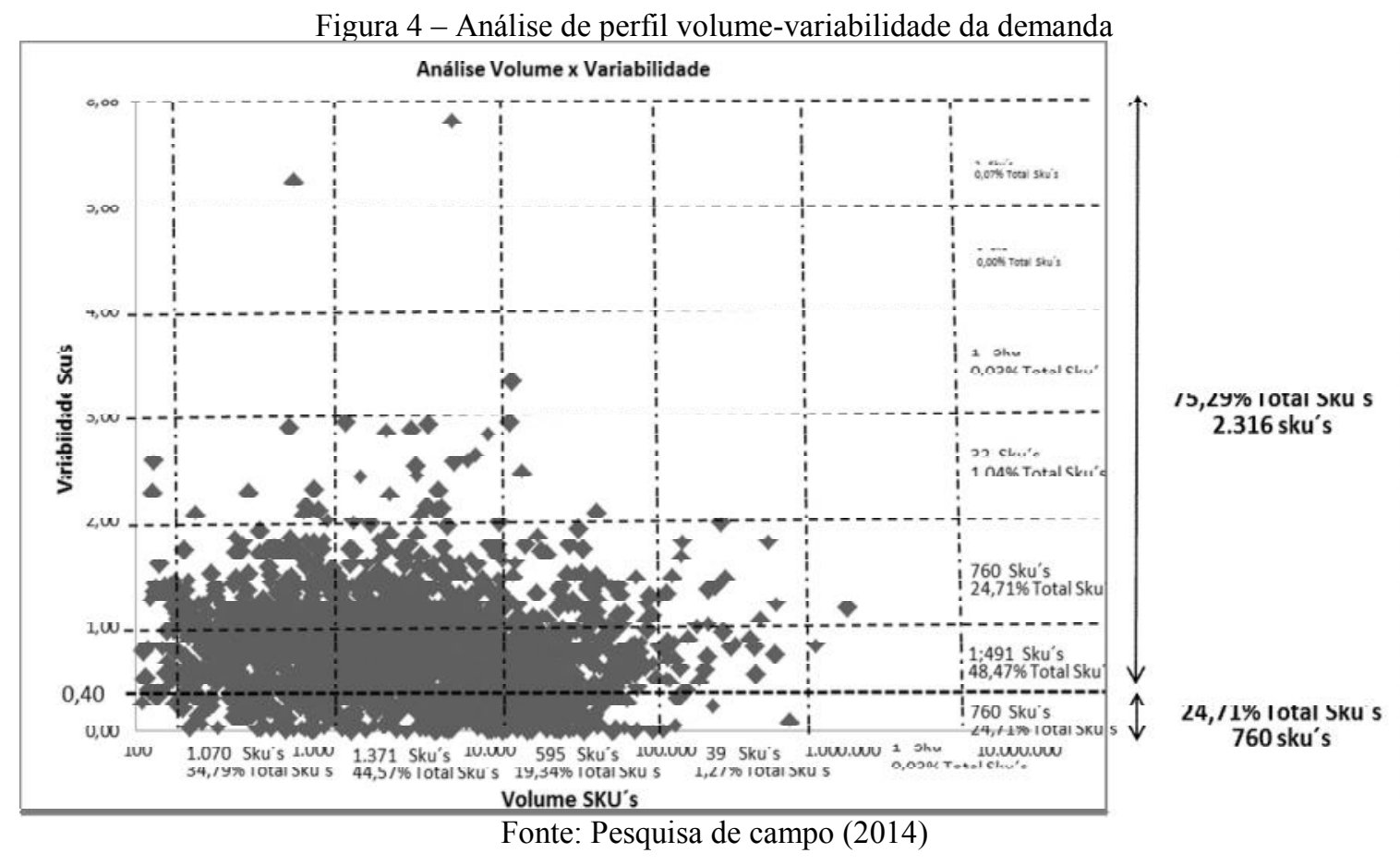

Seguindo a etapa três da metodologia, em seguida, foi necessário definir os diferentes segmentos clientes-produtos com base nos agrupamentos comuns de critérios ganhadores de pedidos (segmentos de clientes) e no perfil da demanda (análise volume-variabilidade) e suas respectivas proposições de valor. Neste estudo de caso, as propostas de valor foram direcionadas pelo nível de flexibilidade que o cliente queria ter na personalização do produto e pelo coeficiente de variação da demanda (CV). Assim, para diferentes níveis de personalização do produto (flexibilidade de customização), o fabricante ofereceu diferentes opções de preço, de variedade de produtos e de prazos de entrega. Depois de analisar a segmentação do produto-cliente, o fabricante estabeleceu quatro segmentos básicos. Com base nas características de cada segmento clienteproduto foi possível oferecer diferentes propostas de valor e desenvolver diferentes estratégias de postergação alinhadas com esses segmentos de cliente-produto. Com base na reestruturação do processo de recebimento do pedido do fabricante, foram selecionados diferentes estratégias de postergação na cadeia de suprimentos a partir do qual cada um dos segmentos seria servido. A 
Figura 5 ilustra o portfólio de postergação com base na abordagem de segmentação cadeia de suprimentos.

Para os produtos de configurações padrão $(\mathrm{CV}<0,2)$ não é permitido qualquer opção de customização dos produtos pelos clientes. Nesse caso, o fabricante permanece realizando previsão de demanda para os itens finais e emprega a estratégia de postergação logística. Neste segmento de clientes-produtos, produtos padrões, com 30 opções são produzidos e distribuídos aos clientes. Este segmento emprega a estratégia de postergação logística onde produtos acabados são armazenados (30 opções) no armazém planta centralizados. Quando os clientes pedem esse tipo de produto, ele é enviado diretamente do inventário para clientes. Neste segmento de clientesprodutos, a proposta de valor oferece um prazo de entrega curto devido à alta disponibilidade, mas um limitado número de opções de motores padrão com preço mais baixo (estratégia de cadeia de suprimentos eficiente).

Para o segmento de opções limitadas $(0,21>\mathrm{CV}<0,40)$ a empresa faz previsões apenas das opções que entraram no produto final. Nesse caso a empresa passou a empregar a estratégia postergação de montagem para lidar com o aumento da variedade de opções de produtos acabados relacionados com este segmento. Neste segmento de clientes-produtos, produtos padrão semiacabados são armazenados na planta e produtos finais são montados de acordo com a escolha do cliente de um leque de opções de características dos produtos finais. A proposta de valor nesse segmento cliente-produto é oferecer duas semanas de tempo de espera, cerca de 600 opções de produtos finais diferentes, com preço baixo (estratégia de cadeia de suprimentos responsiva).

No segmento de clientes-produtos configurado a partir de um catálogo de opções $(0,41>$ $\mathrm{CV}<0,60$ ), os produtos são produzidos quando os clientes escolhem a partir de um catálogo de componentes e peças como personalizar o produto final. Aqui, a empresa empregou uma estratégia de postergação de compras, atrasando a compra de componentes e peças de fornecedores quando o pedido do cliente é colocado. Alguns dos componentes e peças estão em diferentes formas (semiacabados e acabados) e armazenados em diferentes fornecedores. Neste segmento de clientes-produtos, a proposta de valor é oferecer um mês prazo de entrega, cerca de 1.500 opções de produtos finais diferentes com preço de venda médio. 
Figura 5 - Portfólio de postergação para o estudo de caso da cadeia de suprimentos

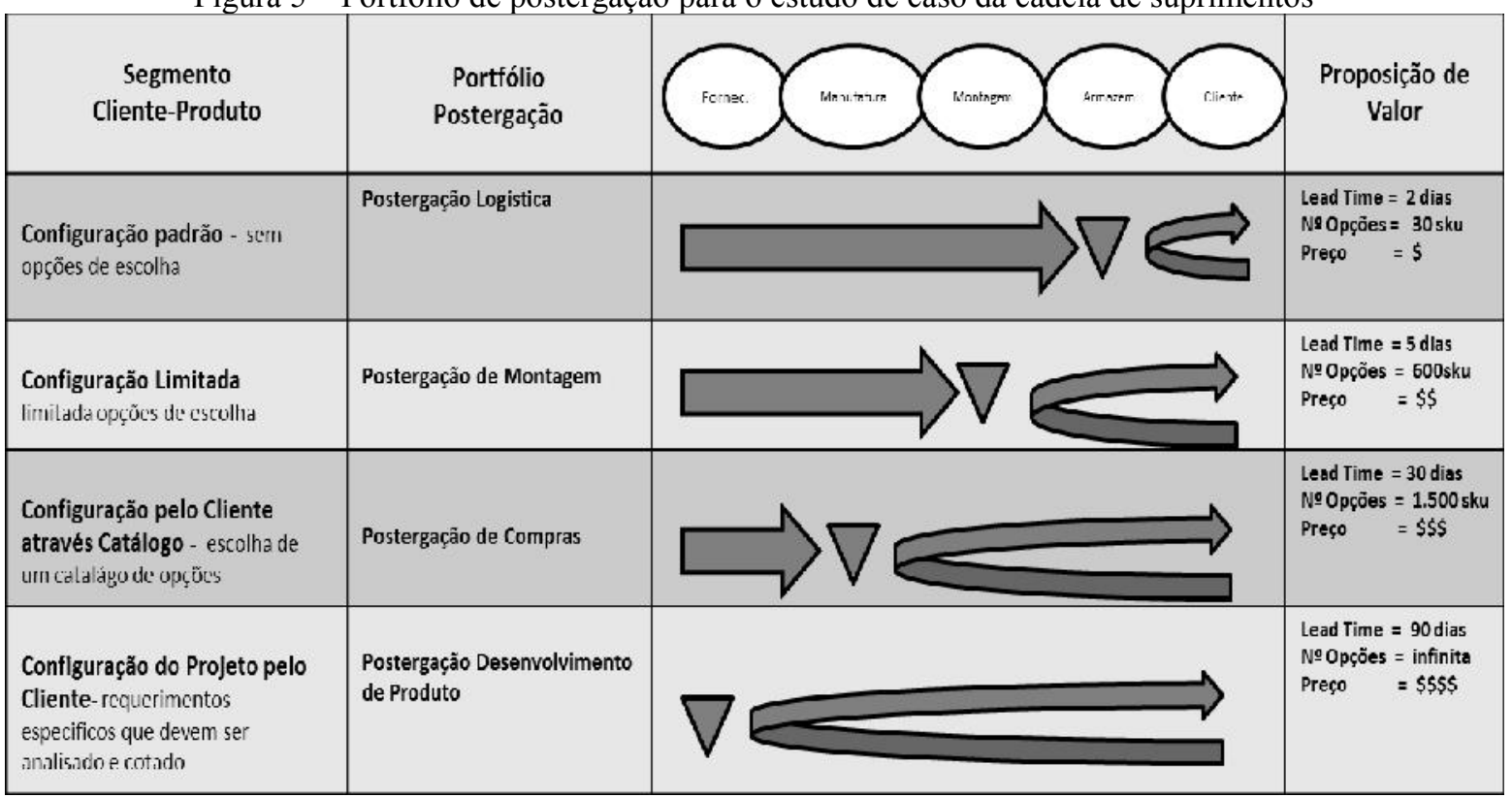

Fonte: Autoria própria (2014)

Por fim, no segmento projetado pelo cliente $(\mathrm{CV}>0,61)$ os requisitos específicos do cliente devem ser analisados e os produtos projetados e cotados. Aqui, a empresa emprega o mais alto nível de postergação usando a estratégia de postergação de desenvolvimento de produto. Neste segmento de clientes-produtos, o processo de design do produto é conduzir pelo pedido do cliente e depende de suas especificações de personalização. Para o sucesso do emprego deste tipo de estratégia de postergação é necessário um alto grau de envolvimento do cliente e dos fornecedores para atingir o alto grau de personalização. Neste segmento de clientes-produtos, a proposta de valor oferta três meses para entregar os produtos, infinitas opções de variedade produtos configurados para o cliente com preço mais elevado que os demais segmentos.

\section{Considerações finais}

O ambiente competitivo está forçando as organizações a adotar novas estratégias para lidar com as mudanças continua do mercado. Diferente das gerações anteriores de cadeias de suprimentos que usavam "um formato serve para todos" nos processos da cadeia de suprimentos e suas proposições de valor, as cadeias de suprimentos modernas sabem que "um formato não serve para todos", e, muitas empresas estão usando os mesmos recursos físicos para atender os clientes e diferenciar produtos serviço através da segmentação da cadeia de suprimentos. Neste artigo, as estratégias de postergação foram associadas com a estratégia da cadeia de suprimentos através da sua segmentação. A segmentação da cadeia de suprimentos deve ser coordenada com a proposição de valor oferecida para cada combinação cliente-produto. $\mathrm{O}$ artigo apresentou uma abordagem para segmentação da cadeia de suprimentos baseada na análise do perfil da demanda (análise 
volume-variedade) e uma ferramenta para auxiliar na seleção de estratégias de postergação impulsionado pelo segmento de clientes-produtos e de suas respectivas proposições de valor.

\begin{abstract}
The stagnation of economy has increased the competition and the uncertainty in the industrial sector. Trends such as increased proliferation of the variety of products and the requirement for customization of products has contributed to difficult the demand forecast. In the new competitive context, it is not possible to employ the more traditional process of supply chain "one-size-fitsall". However, research on supply chains has given relatively little attention to the need to employ different strategies for supply chain business segment. Thus, this article aims to present a methodology for selecting a portfolio of postponement strategies based on targeting the supply chain.
\end{abstract}

Key-words: supply chain; segmentation; postponement; portfolio.

\title{
Referências
}

BOWERSOX, D.J.; CLOSS, D.J. Logistical Management: the Integrated Supply Chain Process. McGraw-Hill, New York: 1996.

BROWN, A. O.; LEE, H. L.; PETRAKIAN, R. Xilinx Improves Its Semiconductor Supply Chain Using Product and Process Postponement. Interfaces, v.3, n. 4, p.65-80, 2000. cross ref

CHILDERHOUSE, P.; AITKEN, J.; TOWILL, D. Analysis and design of focused demand chains. Journal of Operations Management, v.20, p.675-689, 2002. crossref

CHRISTOPHER, M.; TOWILL, D. Developing market specific supply chain strategies. The International Journal of Logistics Management, v.13, n.1, p. 1-14, 2002. crossref

CSCMP. Terms and Glossary, p.212, 2010.

FISHER, M. What is the right supply chain for your product. Harvard Business Review, p.105-116, March/April, 1997.

FULLER, J.; O’CONOR, J.; RAWLINSON, R. Tailored logistics: the next advantage. Harvard Business Review, v.71, n.3, p.87-98, 1995 .

GATTORNA, J. Strategic supply chain alignment: Best practice in supply chain management. Gower (Aldershot, Hampshire, England and Brookfield, VT), p. 671, 1998.

GEARY, S., CHILDERHOUSE, P., TOWILL, D. Uncertainty and the seamless supply chain. Supply chain Management Review, v.6, n.4, p.52-60, 2002.

GODSELL, J.; DIEFENBACH,T.; CLEMMOW,C.; TOWILL, D.; CHRISTOPHER,M. Enabling supply chain segmentation through demand profiling. International Journal of Physical Distribution \& Logistics Management, v. 41, n.3, p.296-314, 2011. crossref

HILlETOFTH, P. How to Develop a Differentiated Supply Chain Strategy. Industrial Management \& Data Systems, v.109, n.1, p.16-33, 2009. crossref

JOHNSON, M.; ANDERSON, E. Postponement Strategies for Channel Derivatives. International Journal of Logistics Management, v.11, n.11, p.19-35, 2000. cross ref 
LAMBERT, D.; GARCÍA-DASTUGUE, S.; CROXTON, K. An evaluation of process-oriented supply chain management frameworks. Journal of Business Logistics, v.26, n.1, p.25-51, 2005. cross ref

LAMBERT, D. M. Supply Chain Management: Processes, Partnerships, Performance, 2 ed., Supply Chain Management Institute, Sarasota, FL, 2006

LEE, H. Aligning supply chain strategies with product uncertainties. California Management Review, 2002. crossref

MELLINS-COHEN, D. Segmentation: a how-to guide. Supply Chain Europe, v. 21, n.1, p.46-49, Jan/Feb, 2012.

MENTZER, J. Understanding demand. Supply Chain Management Review, p. 38-45, May/June, 2004.

MURPHY, P.R.; DALEY, J. Logistics Issues in International Sourcing: An Exploratory Study. International Journal of Purchasing and Materials Management, v.30, n.2, p. 21-27, 1994. crossref

SHAPIRO, R. D. Get leverage from logistics. Harvard Business Review, v.62, p.119-126, 1984.

SIMCHI- LEVI, D.;KAMINSKY,P.; SIMCHI- LEVI,E. Cadeias de suprimentos: projeto e gestão- Conceitos. estratégias e estudo de casos. Porto Alegre: Bookman, 2003.

THOMAS, K. Supply chain segmentation: 10 steps to greater profits. SCMP's Supply Chain Quarterly, Quarter I, 2012.

VAN HOEK, R.I. The rediscovery of postponement: a literature review and directions for research. Journal of Operations Management, v. 19, n. 2, p. 161-184, 2001. crossref

VAN MIEGHEM, J.A.; DADA, M. Price Versus Production Postponement : Capacity and Competition. Management Science, v.45, n.12, p.1631-1649, 1999. crossref

VITASEK, K. L; MANRODT, K. B.; KELLY, K. Solving the supply demand mismatch. Supply Chain Management Review, p.58-64, September/October, 2003.

YANG, B.; BURNS, N. D. Implications of postponement for the supply chain. International Journal of Production Research, v.41, n.9, p. 2075-2090, 2003. crossref

YANG, B.; BURNS, N.D.; BLACKHOUSE, C.J. Postponement: review and an integrated framework. International Journal of Operations \& Production Management, v.24, n.5, p.268-487, 2004. crossref

\section{Dados dos autores}

Nome completo: Luiz Eduardo Simão

Filiação institucional: Universidade Federal de Santa Catarina - UFSC

Departamento: PPGEP - Programa de Pós-gradução em Engenharia de Produção

Função ou cargo ocupado: Estudante Doutorado

Endereço completo para correspondência (bairro, cidade, estado, país e CEP):

Rua Criciúma, $n^{\circ}$ 140, Centro, Itajaí - SC - Brasil - CEP 88303130

Telefones para contato: (47) 33442987

e-mail: luiz.es@posgrad.ufsc.br 
Nome completo: Mirian Buss Gonçalves

Filiação institucional: Universidade Federal de Santa Catarina - UFSC

Departamento: PPGEP - Programa de Pós-graduação em Engenharia de Produção

Função ou cargo ocupado: Professora do Programa de Pós-graduação em Engenharia de Produção

Endereço completo para correspondência (bairro, cidade, estado, país e CEP):

Centro Tecnológico - CTC, Campus Universitário - Trindade - Florianópolis - SC

Caixa Postal 476 - CEP 88040-900

Telefones para contato: (480) 3721-2724

e-mail:mirianbuss@deps.ufsc.br

Submetido em: 23/07/2014

Aceito em: 17/12/2014 